\title{
THE IMPACT OF CLASSROOM TRAINING ON ROAD HAZARDS PERCEPTION IN A TANZANIAN SECONDARY SCHOOL
}

\author{
PAOLO PEREGO, FEDERICA BIASSONI \& MARIA RITA CICERI \\ Università Cattolica del Sacro Cuore di Milano, Italy
}

\begin{abstract}
In Tanzania, in 2014, 3,760 people were killed on the roads, and 14,530 were injured. The possible reasons are to be investigated around the fatalistic beliefs common in Africa, and the lack of effective road safety education in schools. The present study was conducted in a Secondary School in Tanzania in 2016. In January 212 students received a two-hour training held by a traffic psychologist and the training effectiveness was assessed through Static Hazard Perception Test (SHPT), that was submitted before the training and twice after the training, in February and in November (follow up). Aim of the training was to open a 'window of thought' on simple concepts such as road risk and danger, starting from the idea that reflecting on these concepts would help students to improve their awareness of the dangers that can be found on the road. Pre-post repeated measures analysis of variance (ANOVA) yielded a principal effect of the training on hazard perception $(\mathrm{F}(1,210)=27.519, \mathrm{p}<.001)$. Data collected in the follow up show that the level of hazards perception at eight months after the training was lower than immediately after the training (repeated measures ANOVA: $F(1,210)=11,700, p<.005$ ) but higher than before the training (repeated measures ANOVA: $F(1,210)=85,685, p<.001$ ). Although there are some limits, the results suggest that a traffic psychology training about road safety, based on students' reflection about their experience as road users, may help to better recognize hazards on the road and to maintain such ability forward. Such results have implications for more effective road safety education in Africa.
\end{abstract}

Keywords: Tanzania, training, road safety, road hazard, risk perception.

\section{INTRODUCTION}

If we think about the issues most prevalent in Africa, the things that immediately come to mind are hunger, malaria, AIDS and tribal clashes. A recent report by the WHO [1], demonstrates that one of the most significant problems facing Africa is mortality on the roads. About 26 people die every hour because of a road crash in Africa. This is almost two and a half times the European rate.

The data and statistics paint a frightening scenario: African streets are ruled by truck drivers who are often aggressive and violent, committing crimes against others and themselves. Vehicles are used by their owners to intimidate others on and off the roads, which has particularly detrimental effects on drivers of couriers and taxis. In addition, WHO also reports that road rules are largely disobeyed and the laws against driving while intoxicated are never applied. All this leads to significant mortality rates: $16 \%$ of deaths on the roads globally occur in Africa, despite the fact that the African continent holds only $2 \%$ of the world fleet.

In Tanzania, the Police reported that in 2014, over 3760 people were killed on the roads, and a further 14,530 were injured in road related accidents [2]. WHO estimates that the real figure is more than four times as much, with an estimated fatality rate of 32.9 per 100,000 inhabitants, placing Tanzania among the worst five African countries.

Unfortunately, the African political sphere cares little or nothing for the regulation and implementation of African road rules. In fact, many African countries lack even the most 
basic of standards. There are also other problems which are less easily quantifiable, but equally as serious: the lack of knowledge of road signs, the illegal trade in licenses, the purchase of trucks and buses now degraded by the European continent, adulterated petrol, the poor conditions of African roads and also the fatalistic beliefs held by many African people [3]. Most affected by these problems are pedestrians, cyclists, motorcyclists and of course, young Africans who grow up seeing snarled traffic that seems without rules or regulation.

Driver education is the first step to improve the dire situation in Africa. The possibilities presented by educating African drivers are manifold, because of new interventions available to educators around the world.

The present paper explores a road safety education project within a Tanzanian secondary school. The target of the road safety education project is risk perception in students in the secondary school, but also to open a passage to new and prospective studies that will be more targeted.

\section{METHODS}

\subsection{Study area}

This study was undertaken between 17 January and 2 February 2016 and in November 2016 the follow up test was administered. The study was conducted in Suma Secondary School Engikaret, in the District of Longido, Arusha Region in Tanzania. The District of Longido is a rural area of Tanzania which is close to the border of Kenya, and is known as the Masailand.

\subsection{Participants and procedure}

This study was part of the larger "Risk Perception Project" that was conducted in Suma Secondary School Engikaret. Suma Secondary School has about 250 students, who are required to use English exclusively while at school. 212 students (mean age $=15.27 \mathrm{SD}=1.58$, 115 male and 97 female), divided into 4 classes, took part in the study voluntarily and the Director of the school has provided permission for the project to go ahead. Informed verbal consent was sought from respondents before testing commenced.

The students received a two-hour class with a traffic psychologist and the efficacy of the lesson was measured with a pre, post and follow up Static Hazard Perception Test (SHPT).

\subsection{Background of traffic psychologist}

The first author is qualified as a traffic psychologist in Italy and has been working in academic, commercial and volunteer settings in Italy, Tanzania and Australia. He undertakes voluntary work in Tanzania on an annual basis, including work in the Engikaret Secondary School, and was therefore familiar to staff and many students.

\subsection{Lessons in the class}

The aim of the lesson was to open a "window of thought" on simple concepts, such as street, risk and danger. It was hoped that reflecting on these concepts would help improve student awareness of the dangers that can be found on the road [4]. It is also known that the reflection on such topics has the potential to lead to the improvement of the response in a given task [5]. 
To achieve these aims, the training sessions in the classroom were divided into five different tasks to be completed with the students. Tasks 1 to 4 were carried out using a methodology that would allow all students to be able to speak freely, as to express their own idea about the task's key concepts. The four tasks asked definitions, 'what is the road', 'what is a hazard', and "what is a danger". The fourth task asked students to give some examples about hazards while using the road. All the student's answers were then written on the blackboard.

There were some difficulties in conducting this type of lesson due to the limited participation from students, who seemed almost frightened to partake in the questions and answers. The school teachers reported that they had never tried to teach in this way. With students of the first class there also existed language problems. To counteract this, a teacher stood alongside the Traffic Psychologist taking the lesson, and translated from English into Swahili.

For the fifth task the classes were divided into small groups of 8-10 students. Every group had 20 minutes to think of and present an advertisement about 'the right way to cross the road'. The students were free to present the advertisement to the rest of the class using any of the tools that were available to them, including paper, pencil and video making technology (primarily through the use of mobile telephones).

Each group then presented their advertisement to the class. A "jury", composed of various school teachers chose the best advertisement, and presented the winning group with an award. All the advertisements were photographed, filmed and archived. Unlike the first three tasks, there were no difficulties in executing the fifth task. All groups showed enthusiasm for the task and put a lot of effort into the creation and presentation of their advertisements.

\subsection{Measures}

The ability to anticipate traffic situations has been suggested to be an important aspect of driving competence and this ability, commonly termed 'hazard perception', has been measured in different ways. Some studies have measured the road hazard assessment carried out during the presentation of static images [6]. THE SHPT used in this project required participants to indicate, using a sign (participants in the present study were asked to draw a circle), the location of the image where there was a potential safety hazard.

This SHPT was chosen to evaluate the effectiveness of the lessons outlined above for a number of reasons [7]. In particular, this SHPT was chosen for its simplicity and possibility to be conducted without the use of computers or electricity, which are not always available in the School.

The images chosen represent four road situations drawn from videos made in the City of Arusha, and in the village of Sakina in Tanzania (Figs 1-4). The images have been selected because they represent all the following possible sources of danger together: pedestrians, motorcycles and vehicles.

It was the first time that students of the School carried out such kind of work and therefore, not finding alternatives in the scientific literature, we decided to give the subjects 30 seconds to complete the test.

Instructions for carrying out the test were given in English and Swahili and were as follows: "We are going to show you a picture about a road situation. Please put a circle (O) where you think there is a danger" [5]. 


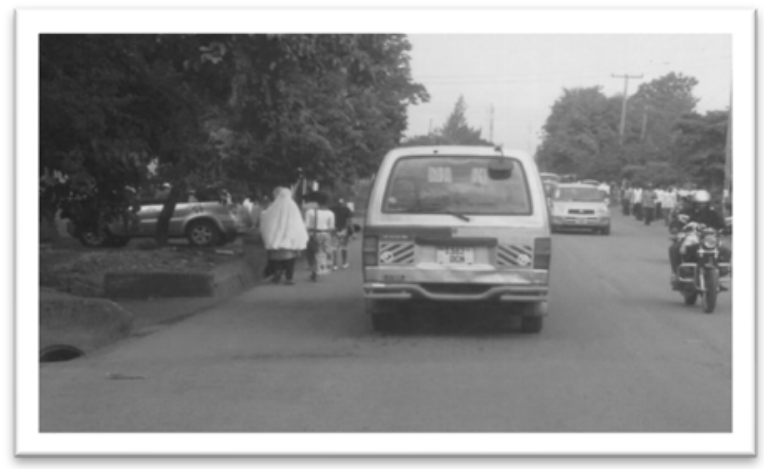

Figure 1: Picture 1(a).

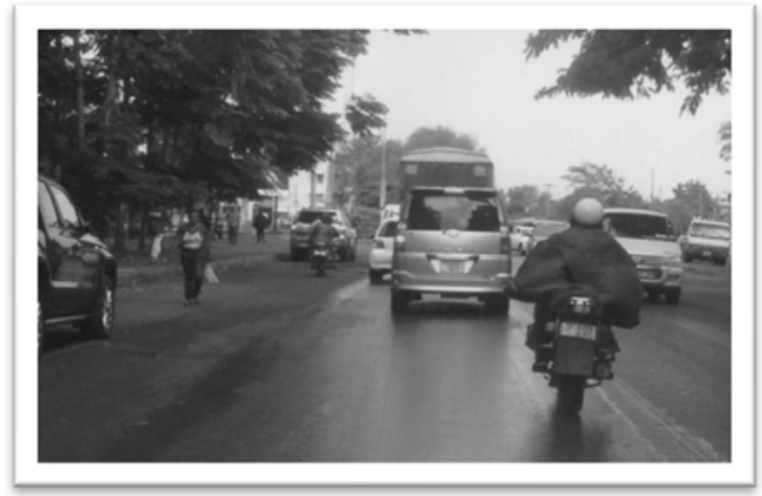

Figure 2: Picture 2(a).

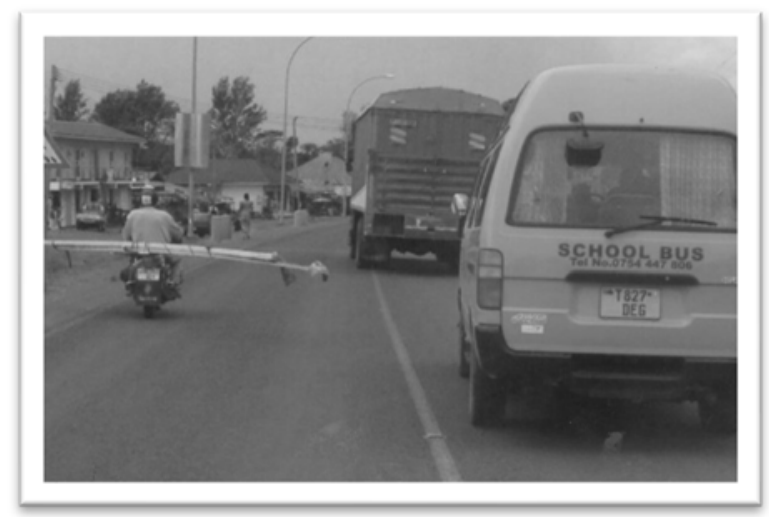

Figure 3: Picture 1(b). 


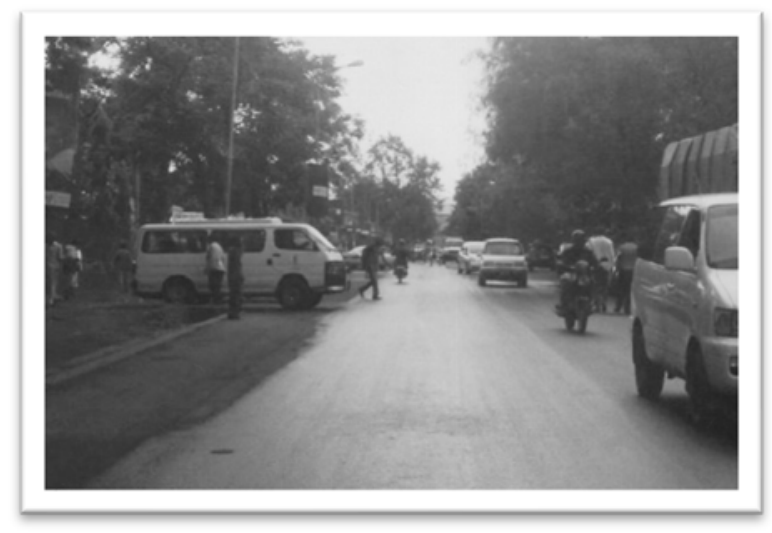

Figure 4: Picture 2(b).

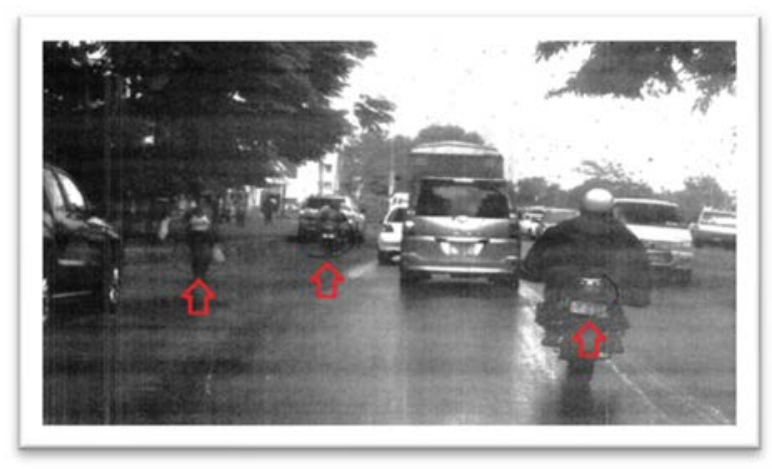

Figure 5: Example of picture used in the SHPT.

Each student was requested to do the SHPT three times: first in a Pre-test before the lesson in the classroom, second in a Post-test after the lesson in the classroom, and thirdly in a Follow-up test in November of the same year (that is nine months later).

Students participating in the Pre-test were given a different picture in the Post-test and in the Follow-up. For example, the student who was given "Picture 1(a)" in the Pre-test was asked to examine "Picture 2(a)" in the Post-test and "Picture 1(b)" in the Follow-up.

During the Pre-test, the SHPT was preceded by a questionnaire collecting some sociodemographic variables such as gender, place of residence (urban or rural) and age. A question about the driving experience of the students with bicycles, motorcycles, cars, trucks and buses was also asked. The filling in of the questionnaire required in some cases the investigator's help, particularly with the first class where knowledge of the subject area. was very low and the students had difficulty speaking in English (Fig. 6). 1 May 2017. 


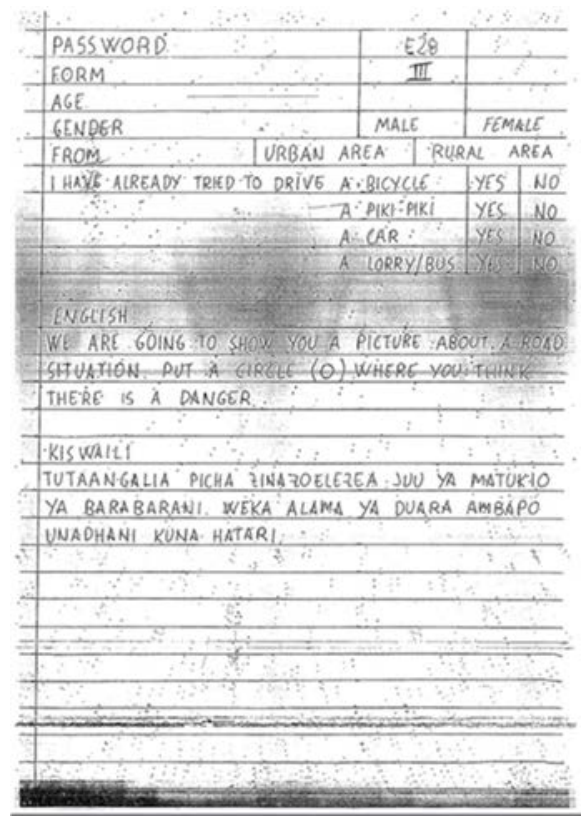

Figure 6: Picture 6.

\section{RESULTS}

The socio-demographic data and the road experience data were summarized in Table 1, as well the average value of the recognized hazards. The data were collected through the questionnaires and the average value of the recognized hazard through the SHPT.

Table 1: Results of the questionnaire and average of the recognized hazard in the SHPT.

\begin{tabular}{|l|l|l|l|l|l|l|l|l|}
\hline & \multicolumn{3}{|l}{ Students } & Age & \multicolumn{2}{l|}{ From } & \multicolumn{2}{l|}{ Bicycle } \\
\cline { 2 - 10 } & $\mathrm{M}$ & $\mathrm{F}$ & Tot & & $\begin{array}{l}\text { Urba } \\
\mathrm{n}\end{array}$ & Rural & Y & $\mathrm{N}$ \\
\hline Form 1 & 30 & 26 & 56 & 13,98 & 31 & 25 & 40 & 16 \\
\hline Form 2 & 37 & 37 & 74 & 14,82 & 42 & 32 & 59 & 15 \\
\hline Form 3 & 19 & 20 & 39 & 15,85 & 25 & 14 & 33 & 6 \\
\hline Form 4 & 29 & 14 & 43 & 17,21 & 24 & 19 & 39 & 4 \\
\hline Total & 115 & 97 & 212 & 15,27 & 122 & 90 & 171 & 41 \\
\hline & Piki-Piki & Car & \multicolumn{7}{l|}{ Lorry } & Hazard \\
\cline { 2 - 10 } & $\mathrm{Y}$ & $\mathrm{N}$ & $\mathrm{Y}$ & $\mathrm{N}$ & Y & $\mathrm{N}$ & Pre & Post \\
\hline Form 1 & 3 & 53 & 3 & 53 & 0 & 56 & 1,34 & 3,04 \\
\hline Form 2 & 23 & 51 & 8 & 66 & 1 & 73 & 1,65 & 3,00 \\
\hline Form 3 & 4 & 35 & 4 & 35 & 0 & 39 & 1,31 & 2,82 \\
\hline Form 4 & 26 & 17 & 14 & 29 & 4 & 39 & 1,65 & 3,23 \\
\hline Total & 56 & 156 & 29 & 183 & 5 & 207 & 1,51 & 3,02 \\
\hline
\end{tabular}




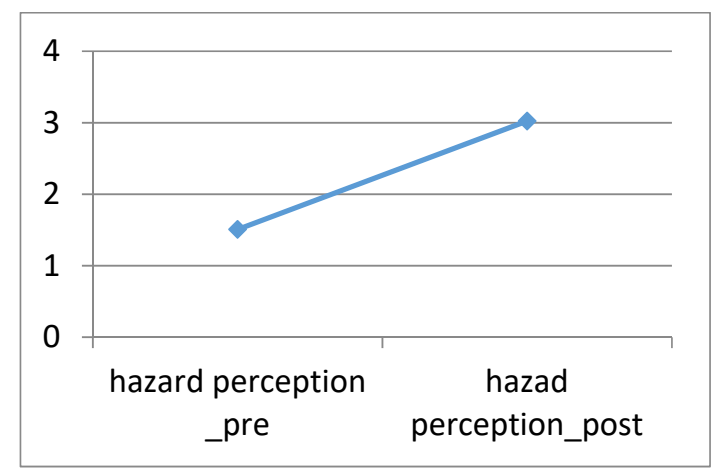

Figure 7: Hazard perception pre- and post-training.

A first comparison of the results was made for the average results between Pre-test and Post-test. Repeated measures analysis of variance (ANOVA) yielded a principal effect of the training on hazard perception $\left(\mathrm{F}(1,210)=27.519, \mathrm{p}<.001\right.$, partial $\eta^{2}=.141$, observed power $=.999$ ), indicating that after taking part in the training the students detected significantly more hazards than they did before (Fig. 6). There was no interaction effect of training with any socio-demographic variable nor with the global driving experience level: the training proved to be effective independently of the considered features of the participants (gender: $\mathrm{F}$ $(1,210)=1.432, p=.233$, partial $\eta^{2}=.009$, observed power $=.221$; place of residence: $F(1,210)$ $=0.026, \mathrm{p}=.872$, partial $\eta^{2}=0$, observed power $=.053$; form: $\mathrm{F}(3,210)=0.213, \mathrm{p}=.887$, partial $\eta^{2}=.004$, observed power $=.089$; global driving experience level: $F(4,210)=0.846, p=.498$, partial $\eta^{2}=.020$, observed power $=.266$ ).

Data collected in the follow up show that the level of hazards perception at nine months after the training was lower than immediately after the training (repeated measures ANOVA: $\mathrm{F}(1,210)=11,700, \mathrm{p}<.005)$ but higher than before the training (repeated measures ANOVA: $\mathrm{F}(1,210)=85,685, \mathrm{p}<.001)$.

\section{DISCUSSION}

The initial idea of the project was to introduce new issues into the road hazard perception in a Tanzanian school and investigate whether this type of lesson could increase the results obtained in a static hazard perception test and therefore in some way raise awareness in young students.

Data collected during the administration of Pre-test, Post-test and Follow-up show an improvement in the analysis of risk situations. Although there are some limits in the research, the data also put into evidence that the lesson with the Traffic Psychologist might have helped the subjects to start thinking about their user experiences of the road, about what may be considered a danger and how to more easily recognise a possible road hazard [8].

Data collected about socio-demographic variables in the Pre-test indicate a foregone conclusion: that the differences in socio-economic conditions existing between the third world countries and industrialised countries are enormous. But, although it has been suggested that the social and demographic characteristics would influence the perception of risk, few studies have been conducted on this issue [9].

For example, the data collected about the use of bicycles showed that 41 students out of 212 (19.3\% of the sample), most of all adolescents, have never ridden a bicycle. These are 
stunning results, bearing in mind that the questionnaire did not ask if a bicycle was used daily (a question that might have been asked of European participants of the questionnaire) but rather if one had ever been used. Surely not having ever experienced to ride a bicycle on the road would diminish the possibility of participants to store potential dangerous situations in their mind, which would then be drawn on as users of the road, either as a pedestrians or drivers of motor vehicles [10].

Notwithstanding this, the results of the Follow-up test showed an increased ability of participants to recognise risky situations on the road after the training. This data is perhaps more comforting for future road safety projects, which will definitely benefit from the experience gained with this first intervention.

\subsection{Limits}

The construction and administration of the SHPT have some limitations due to the type of test which, as mentioned earlier, was also chosen for 'environmental' reasons associated with reaching a highland in Tanzania where technology is not always readily available.

The study of the data collected showed that the figure $1 \mathrm{~b}$ was ambiguous to the participants because of the presence of various dangers in the foreground, in particular the motorcycle with the badly placed load. The presence of these dangers in the foreground distracted the subject from searching for any other dangerous situations that may have been further present in the image.

The presence of a control group, would have enhanced the validity of the results. In the present work, the choice to give all the students the opportunity to take part in the training is a consequence of the stated objective: to introduce and test in the field a new way of educating for improved road safety in the African context.

\section{ACKNOWLEDGEMENT}

The authors wish to thank the Rev. Renatus Karumuna director of the Suma Secondary School who made this research possible.

\section{REFERENCES}

[1] WHO. United Republic of Tanzania: Country Profile. World Health Organization, downloaded from http://www.who.int/violence_injury_prevention/road_safety status/2015/countryprofiles/United_Republic_of_Tanzania.pdf, 2015.

[2] Tanzanian Traffic Police, Statistics available directly from Traffic Police Headquarters, Sokoine Drive, Dar es Salaam, Tanzania, 2015.

[3] Lamont, M., Accidents Have No Cure! Road Death as Industrial Catastrophe In Eastern Africa, African Studies, 71(2), 174-194, 2012.

[4] Slovic, P., The Perception of Risk. Risk, Society, and Policy Series, 2000.

[5] Zepeda, C.D., Richey, E.J., Ronevich, P. \& Nokes-Malach, T.J., Direct instruction of metacognition benefits adolescent science learning, transfer, and motivation: An in vivo study. Journal of Educational Psychology, 107(4), 954-970, 2015.

[6] Tränkle, U., Gelau, C. \& Metker, T., Risk perception and age-specific accidents of young drivers. Accident Analysis \& Prevention, 22(2), pp. 119-125, Apr. 1990.

[7] Malone, S. \& Brünken R., Assessment of driving expertise using multiple choice questions including static vs. animated presentation of driving scenarios. Accident Analysis \& Prevention, 51, pp. 112-119, 2013.

[8] Slovic, P., 2010. The Feeling of Risk. New Perspectives on Risk Perception. Earthscan risk in society series. 
[9] Millstein, S.G. \& Halpern-Felsher, B.L., Perceptions of risk and vulnerability. Journal of Adolescentes Health, 31(1), pp. 10-27, 2002.

[10] Dake, K., Orienting Dispositions in the Perception of Risk: An Analysis of Contemporary Worldviews and Cultural Biases. Journal of Cross-Cultural Psychology, 22(1), pp. 61-82, 1991. 